\title{
Effect of PWHT with Sheet-Type Ceramic Heater on Compressive Behaviors of Non-Stiffened Welded Steel Box Columns
}

\author{
May Phyo Aung, Mikihito Hirohata \\ Graduate School of Engineering, Nagoya University, Nagoya, Japan \\ Email: aung.may.phyo@e.mbox.nagoya-u.ac.jp,hirohata@civil.nagoya-u.ac.jp
}

How to cite this paper: Aung, M.P. and Hirohata, M. (2018) Effect of PWHT with Sheet-Type Ceramic Heater on Compressive Behaviors of Non-Stiffened Welded Steel Box Columns. World Journal of Engineering and Technology, 6, 50-67. https://doi.org/10.4236/wjet.2018.61003

Received: November 13, 2017

Accepted: January 21, 2018

Published: January 24, 2018

Copyright $\odot 2018$ by authors and Scientific Research Publishing Inc. This work is licensed under the Creative Commons Attribution International License (CC BY 4.0).

http://creativecommons.org/licenses/by/4.0/

\begin{abstract}
A series of fundamental experimental investigation was conducted in order to examine the effect of PWHT by sheet-type ceramic heater on the residual stress, deformation and compressive behavior of non-stiffened welded box columns. The sheet-type ceramic heater was able to control the required temperature history for PWHT with high accuracy. The welding-induced tensile and compressive residual stresses of the specimens were reduced by $90 \%$ and $76 \%$ respectively with PWHT. Besides, PWHT could reduce the welding-induced out-of-plane deformation by $22 \%$. It was revealed that the PWHT specimens had a slight higher stiffness than the As-welded specimens when applying monotonic static compressive load on both As-welded and PWHT specimens. They could also enhance the ultimate compressive load capacity about $32 \%$ of that of the As-welded specimens. The effectiveness of PWHT with the sheet-type ceramic heater could be confirmed.
\end{abstract}

\section{Keywords}

Residual Stress, Out-of-Plane Deformation, PWHT, Sheet-Type Ceramic Heater, Welded Box Column

\section{Introduction}

Welded open sections and closed sections have been generally used in steel buildings and bridge constructions due to a limitation of size availability in the rolled shaped sections. The welded box sections are extensively used for the structural members such as columns in the buildings and arch ribs in the steel bridges to resist the compressive load. Since steel plates are assembled to create the box sections, extensive welding is inevitably required. In addition to the new 
fabrication, welding is prevalently adopted for repair works on the existing steel structures. For example, in the aging steel structures especially steel bridges, damage and deterioration have been reported because of fatigue cracks and corrosion [1] [2] [3]. These two factors have an adverse effect on the performance of the members since fatigue cracks are the main cause of fatigue failure while corrosion reduces the sectional area of the members, resulting in failure due to strength reduction of the members. Consequently, the additional members for the repair works are joined with high strength bolts due to the quality assurance. However, bolts subject the weight increase to the structures and drilling to base metal is required. Besides, bolts are difficult to work for the narrow parts and complicated portions. Thus, welding is strongly expected as an alternative joining method for the repair works.

During the welding process, the changes in properties of the base metal are introduced due to heat input while thermal stresses and strains are produced because of the different cooling rates at the different locations of the base metal. Due to the thermal contraction during cooling stage, tensile residual stresses are induced at the weld vicinity and the heat affected zone (HAZ) whereas balancing compressive residual stresses are observed away from the weld line. The tensile residual stresses deteriorate the fatigue strength while the balancing compressive residual stresses deplete the load-carrying capacity of the members when the compressive loads are applied to the welded members. Generally, the welded box sections are composed of thin plates, consequently, distortions are generated due to the welding, resulting in imperfection to the members and affecting the stiffness and strength of the members. Hence, it is of priority concern to evaluate and alleviate the welding-induced residual stresses and distortions [4]-[12].

It is well known that the reduction of the welding-induced residual stresses is effective for ensuring and enhancing the structural performances such as fatigue durability and load-carrying capacity of the steel members. Therefore, several kinds of residual stress reduction methods have been proposed. For example, shot peening on the weld toe generates compressive stress field locally and it is effective for improving the fatigue strength of the welded joints [13]. On the other hand, stress release annealing known as post-weld heat treatment (PWHT) is helpful for reducing the whole residual stress in the member.

PWHT is generally employed for pressure vessels and pipelines, and is rarely applied to the civil engineering structures as steel bridges since it is commonly carried out in the factory with the large scale electric and flame furnaces by putting the whole members into them to provide the heat treatment. Wang and Qin [14] conducted the experimental investigation on the thin-walled welded $\mathrm{H}$-sections to examine the effect of PWHT on the residual stress by employing the electric furnace while PWHT was applied to the high strength welded connections by utilizing the laboratory heating furnace [15]. Besides, some researchers have been conducted to evaluate the effect of PWHT on the residual stresses in the steel plates and welded joints [16] [17] [18] [19]. However, there is 
a need for an alternative heat source when it is not possible to apply PWHT with the furnaces for the repair works at the existing steel bridge structures.

Then, the sheet-type ceramic heater has been noted as a portable heat source for PWHT because it can be applicable for the localized heat treatment in the existing structures. An application of sheet-type ceramic heaters on the welded steel plates and steel deck was realized for the purpose of improvement of fatigue performance by relaxing the residual stresses [20] [21] [22].

The heat source chosen for this study was intended for a future application in the localized heat treatments and repair works for the existing steel bridges and the complicated structures. Besides, the heat source must be applicable at the sites for both new and existing structures. On top of that, the heat source must be able to control the required temperature history with high accuracy. The sheet-type ceramic heater used in this study is expected to satisfy the aforementioned conditions.

A fundamental experimental investigation was conducted in order to examine the effect of PWHT by the sheet-type ceramic heater on the residual stresses, the deformation and compressive behavior of the non-stiffened welded box columns in this study.

\section{Experiment}

\subsection{Test Specimens}

In this study, six identical stub columns were fabricated from JIS G3101 SS400 steel plates. Their walls were $4.5 \mathrm{~mm}$ thick, and top and bottom cover plates were $12 \mathrm{~mm}$ thick. The shape and dimensions of the specimens were shown in Figure 1. JIS Z3312 welding wires for the general carbon steel were used to perform the fillet welding for creating the non-stiffened welded box columns. Chemical compositions of the base metal and welding wire for the specimens are presented in Table 1 in which the welding wire compositions were based on the catalogue value. In this experiment, $\mathrm{CO}_{2}$ semi-automatic welding was performed with the current of $120 \mathrm{~A}$, the voltage of $20 \mathrm{~V}$ and the average welding speed of $5.7 \mathrm{~mm} / \mathrm{s}$.

Before creating the box columns, three sizes of plates such as $200 \times 200 \times 4.5$ $\mathrm{mm}$ plates and $230 \times 200 \times 4.5 \mathrm{~mm}$ plates for walls and $250 \times 250 \times 12 \mathrm{~mm}$ plates for top and bottom covers were prepared first. Wall plates were connected to the top and bottom cover plates with the application of the fillet weld. Before the final longitudinal welding on the wall plates, tack weld was applied to the wall plate joints in order to maintain the correct positions and dimensions.

Table 1. Chemical compositions.

\begin{tabular}{ccccccc}
\hline \multirow{2}{*}{ Metal } & \multicolumn{5}{c}{ Chemical compositions (Mass \%) } \\
\cline { 2 - 6 } & $\mathrm{C}$ & $\mathrm{Si}$ & $\mathrm{Mn}$ & $\mathrm{P}$ & $\mathrm{S}$ \\
\hline Base metal & 0.16 & 0.02 & 0.48 & 0.015 & 0.005 \\
Weld metal (Catalogue value) & 0.08 & 0.62 & 1.12 & 0.010 & 0.008 \\
\hline
\end{tabular}



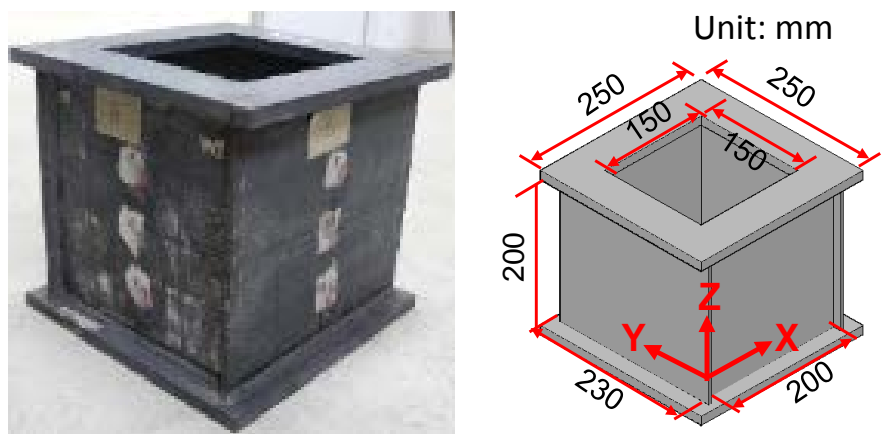

(a)

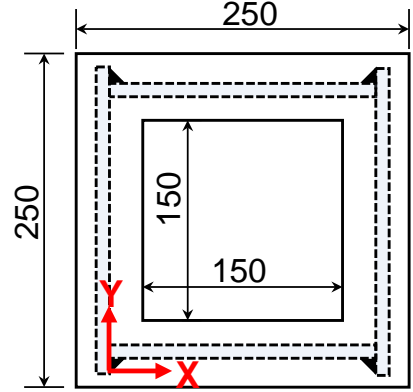

(b)

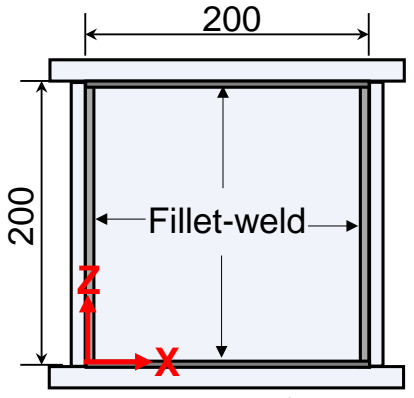

Panel A \& C

(d)

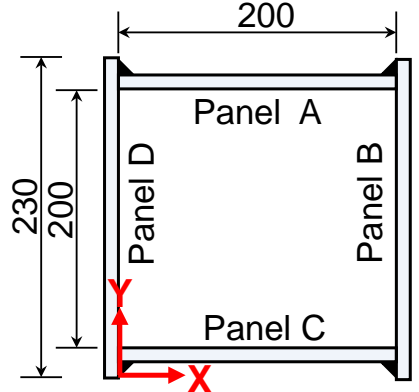

(c)

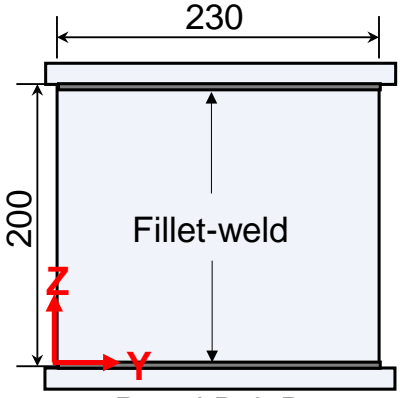

Panel B \& D

(e)

Figure 1. Experimental test specimen. (a) 3D view; (b) Plan view; (c) Mid-height view; (d) Front view; (e) Side view.

Then, all specimens were put into an electric furnace to relax the residual stresses at the top and bottom cover plate connections. After the stress relaxation, the final longitudinal welding was performed with the continuous fillet welding to the wall plates in order to create the welded steel box columns.

\subsection{Post-Weld Heat Treatment}

Three numbers of As-welded (AW) specimens were used as benchmarks and post-weld heat treatment (PWHT) was applied on another three specimens. It was assumed that normal ready-fabricated furnaces sometimes could not be applied on the welded part of the existing structures. Considering this kind of condition in the authentic structures, the sheet-type ceramic heater shown in Figure 2 was used. It is possible to use a small and portable generator at the site for PWHT with ceramic heater. Besides, it can be assembled to a flexible size and 


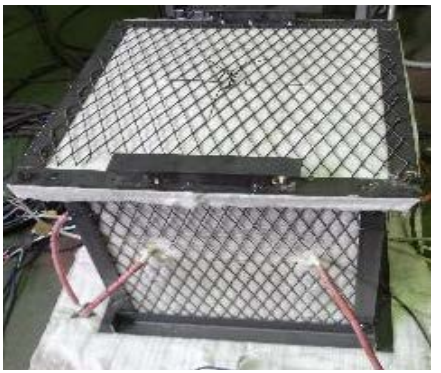

(a)

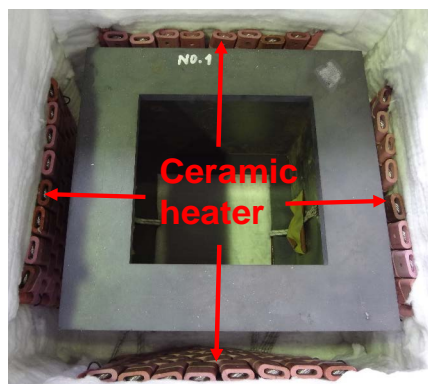

(c)

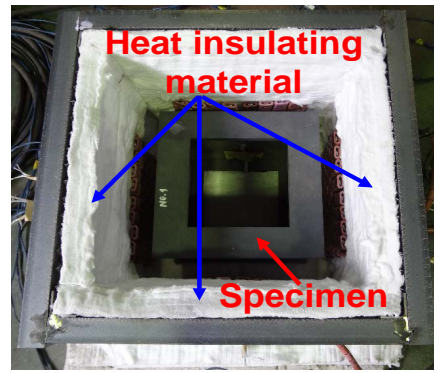

(b)

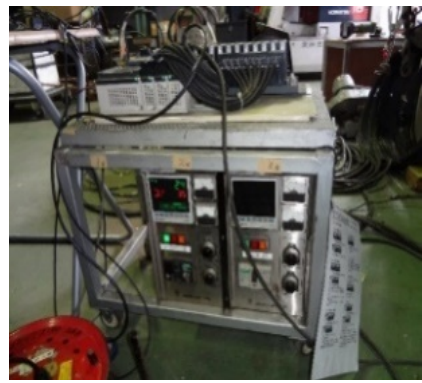

(d)

Figure 2. Post-weld heat treatment system. (a) Steel case; (b) Heat insulating material; (c) Sheet-type ceramic heater; (d) Temperature control device.

shape, and easily applied to the welded portions having the complicated shapes. On top of that, it is highly safe in work since no fire flame is used like gas burner, and very good in workability. A steel case was prepared for setting the ceramic heater to encompass all panels of the box columns. Heat insulating materials were accommodated in all sides and top and bottom of the steel case in order to keep the heat for the specimens during applying PWHT. Thermocouples were attached to the outside and inside faces of the specimens to measure the temperature history during PWHT and to examine the temperature distribution through the thickness (Figure 3). The specimens were put into the case individually, then the sheet-type ceramic heaters were placed to the outside face of each panel of the specimens, eventually PWHT was performed according to JIS standard specification via the ceramic heater by operating a temperature control device.

Table 2 represents the limitation of temperature for PWHT by JIS. According to JIS Z3700, the heating rate should not be more than $220^{\circ} \mathrm{C} / \mathrm{hr}$ and the cooling rate should not be higher than $280^{\circ} \mathrm{C} / \mathrm{hr}$ at $425^{\circ} \mathrm{C}$ or higher [23]. The minimum soaking temperature should be $595^{\circ} \mathrm{C}$ and the minimum soaking time should not be less than the hour that is divided the thickness of weld throat in $\mathrm{mm}$ by 25. Hence, the soaking temperature was set as $600^{\circ} \mathrm{C}$ and PWHT was performed with the rate of $150^{\circ} \mathrm{C} / \mathrm{hr}$ at $425^{\circ} \mathrm{C}$ or higher to the target temperature. When the temperature of the specimens reached to $600^{\circ} \mathrm{C}$, the specimens were soaked about $1 \mathrm{hr}$. After soaking, the specimens were cooled down with the rate of $150^{\circ} \mathrm{C} / \mathrm{hr}$ again until $425^{\circ} \mathrm{C}$. Finally, the specimens were cooled down gradually until the ambient temperature. During applying PWHT, temperature history was recorded by thermocouples which were attached to the specimens. 


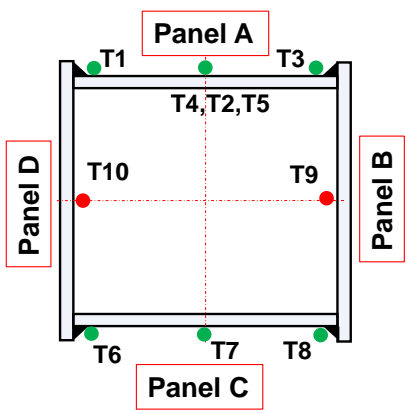

(a)

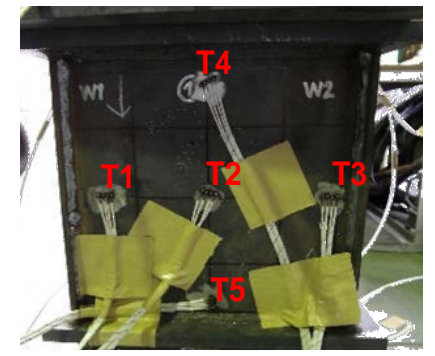

(b)

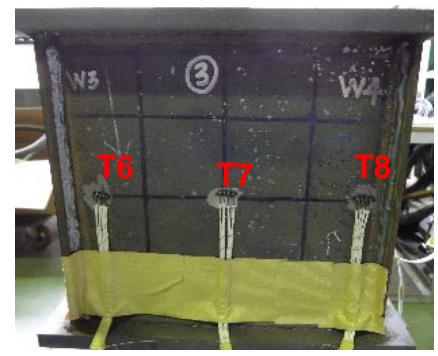

(d)

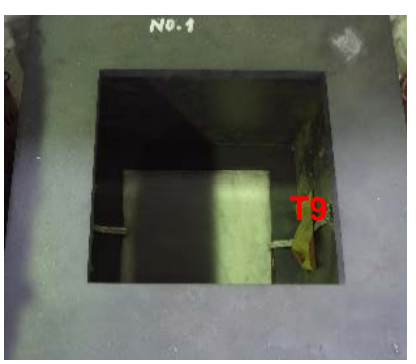

(c)

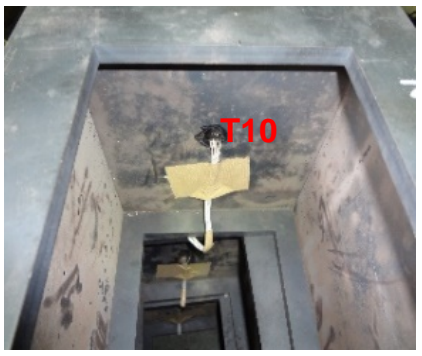

(e)

Figure 3. Position of thermocouples. (a) Plan view; (b) Panel A; (c) Panel B; (d) Panel C; (e) Panel D.

Table 2. JIS temperature limitation and experimental condition.

\begin{tabular}{ccc}
\hline Specification & JIS Z 3700 & Experiment \\
\hline Heating rate $\geq 425^{\circ} \mathrm{C}$ & $\leq 220^{\circ} \mathrm{C} / \mathrm{hr}$ & $150^{\circ} \mathrm{C} / \mathrm{hr}$ \\
Cooling rate $\geq 425^{\circ} \mathrm{C}$ & $\leq 280^{\circ} \mathrm{C} / \mathrm{hr}$ & $150^{\circ} \mathrm{C} / \mathrm{hr}$ \\
Min soaking temp. & $595^{\circ} \mathrm{C}$ & $600^{\circ} \mathrm{C}$ \\
Min soaking time & $\mathrm{t} / 25$ & $1 \mathrm{hr}$ \\
\hline
\end{tabular}

${ }^{*}$ where $t$ is weld throat thickness $(\mathrm{mm})$.

Figure 4 expresses the temperature history of one of the PWHT specimens during PWHT. It was revealed that the sheet-type ceramic heater was able to control the temperature history for PWHT accurately. There was no temperature difference between the heated sides and unheated sides in all specimens since all thermocouples mounted on the outside and inside faces of panels exhibited the same temperature distribution throughout the history. That means the sheet-type ceramic heater could provide the same temperature to both contact and non-contact faces. 


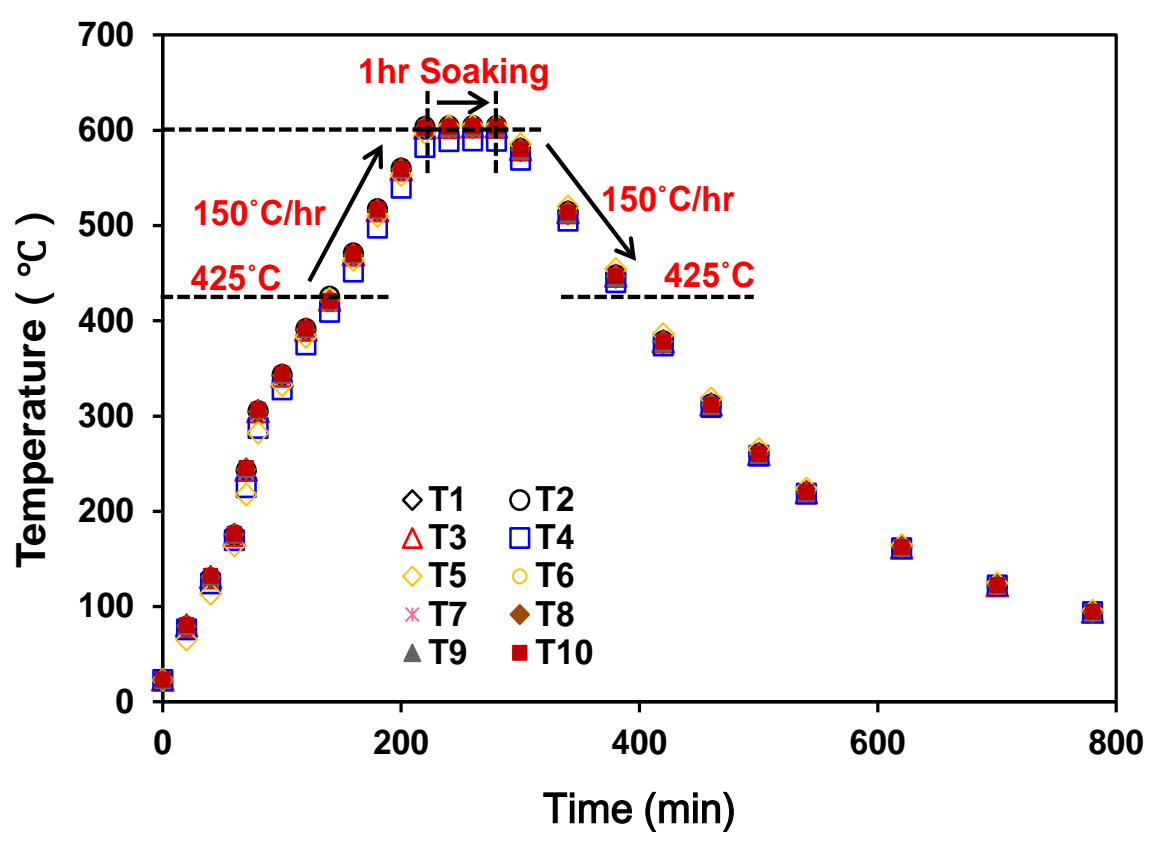

Figure 4. Temperature history.

\subsection{Out-of-Plane Deformation Measurement}

Before commencement of the loading test, out-of-plane deformations before and after PWHT were measured in order to investigate the effect of PWHT on welding-induced deformation. The out-of-plane deformation measurement was conducted manually at each panel of the specimen by using a depth gage set on a steel frame as a reference surface. The deformations were plotted along the centerline of all panels in the longitudinal direction. It was found that the modes of deformation generated by welding before and after PWHT were similar, but PWHT slightly reduced the welding-induced deformations (Figure 5). The maximum average deformations of the AW and PWHT specimens are shown in Table 3. The peak values at the panel A \& $\mathrm{C}$ and B \& D after welding (before PWHT) were $0.45 \mathrm{~mm}$ and $0.29 \mathrm{~mm}$ respectively whereas they were about 0.35 $\mathrm{mm}$ and $0.24 \mathrm{~mm}$ after PWHT. Hence, PWHT could reduce the out-of-plane deformation about $22 \%$ at the panel A \& C and $17 \%$ at the panel B \& D.

\subsection{Vickers Hardness Test}

Vickers hardness test was conducted on the welded parts of the AW and PWHT specimens in order to verify whether PWHT was performed successfully. The hardness was measured four times at each point and the average hardness values and standard deviations of the AW and PWHT specimens are illustrated in Figure 6. It was observed that PWHT reduced noticeably the hardness values at the heat affected zone (HAZ) of the base metal. Although the maximum hardness value at $\mathrm{HAZ}$ after welding ranged from $201 \mathrm{HV}$ to $230 \mathrm{HV}$, it remarkably decreased to $163 \mathrm{HV}$ after PWHT. Hence, Vickers hardness test proved that PWHT with the sheet-type ceramic heater was performed properly. 


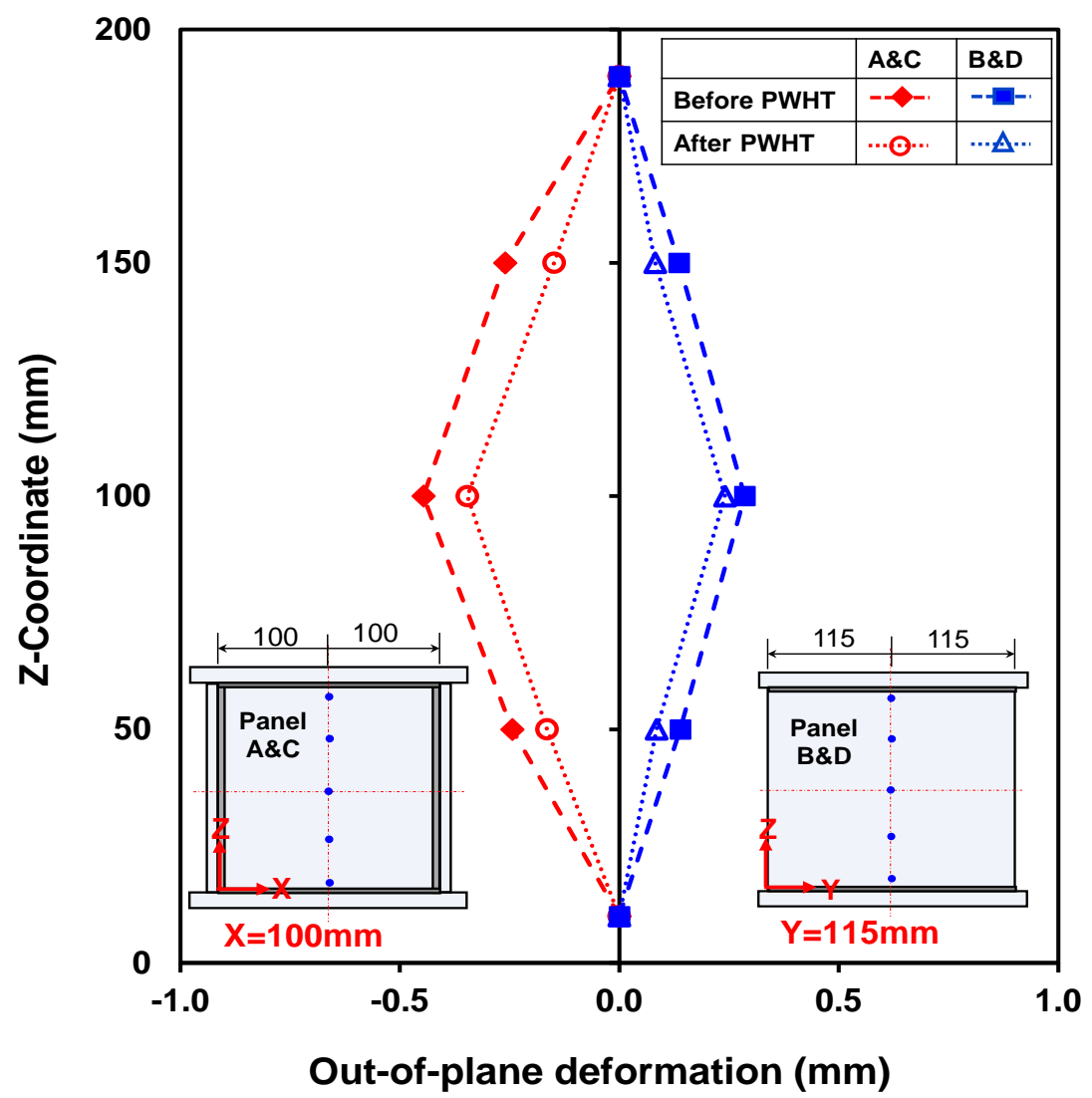

Figure 5. Average out-of-plane deformation before loading.

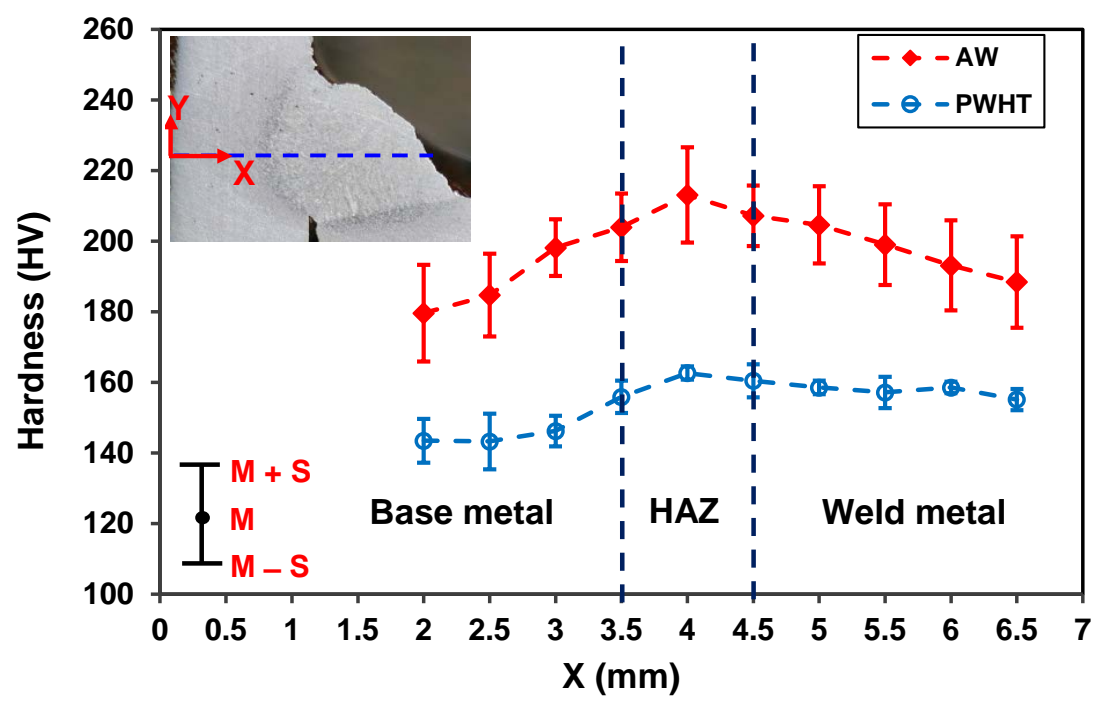

Figure 6. Results of Vickers hardness test.

Table 3. Out-of-plane deformation before loading ( $\mathrm{mm})$.

\begin{tabular}{ccccc}
\hline Specimen & \multicolumn{2}{c}{ AW } & \multicolumn{2}{c}{ PWHT } \\
\hline Panel & A \& C & B \& D & A \& C & B \& D \\
\hline Average & -0.45 & 0.29 & -0.35 & 0.24 \\
(Standard deviation) & $(0.26)$ & $(0.25)$ & $(0.14)$ & $(0.29)$ \\
\hline
\end{tabular}




\subsection{Tensile Test}

Three numbers of coupons were cut from the wall panels of each of the AW and PWHT specimens in order to investigate the changes of mechanical properties by PWHT. The nominal stress versus strain curves from a tensile test are depicted in Figure 7. While the average yield stresses for both AW and PWHT specimens were almost the same, the tensile strength of the PWHT specimens was slightly lower than that of the AW specimens. Mechanical properties of the AW and PWHT specimens resulted from the tensile test are summarized in Table 4. Same modulus of elasticity (201 GPa) was observed in both AW and PWHT specimens and their elongations were $31 \%$ and $34 \%$ respectively. Therefore, it was pointed out that there were no significant changes in mechanical properties by PWHT.

\subsection{Residual Stress Measurement by X-Ray Diffraction Method}

Residual stresses of the AW and PWHT specimens were measured by applying $\mathrm{X}$-ray diffraction method (XRD) and XRD measurement points are shown in Figure 8. The accuracy of XRD method depends on the surface smoothness and the grain sizes, and it is unlikely to measure at the welded points. Thus, XRD measurement was conducted $30 \mathrm{~mm}$ away from the mid-height of the specimens in order to avoid the welded points of the thermocouples.

Figure 9 and Figure 10 show the residual stress distribution along the longitudinal and transverse directions. As predicted, in the AW specimens, high tensile residual stresses were found near the weld vicinity with $170 \mathrm{MPa}$ in the panel A \& $\mathrm{C}$ and $235 \mathrm{MPa}$ in the panel $\mathrm{B} \& \mathrm{D}$, and the maximum compressive residual

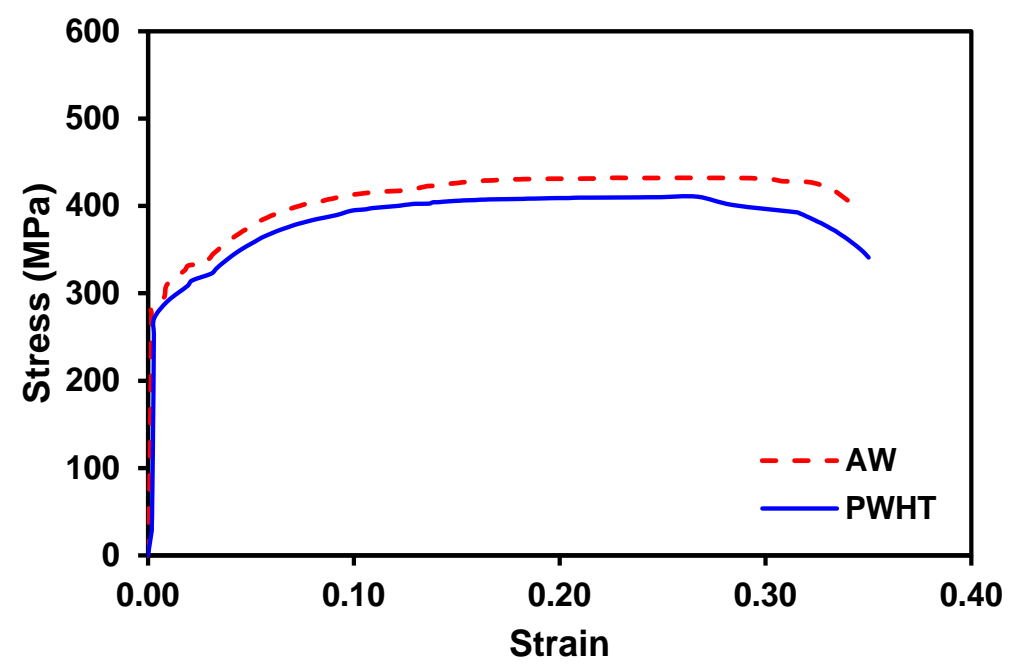

Figure 7. Stress-strain curve from tensile test.

Table 4. Mechanical properties from tensile test.

\begin{tabular}{ccccc}
\hline Specimen & $\sigma_{\mathrm{y}}(\mathrm{MPa})$ & $\sigma_{\mathrm{u}}(\mathrm{MPa})$ & $\mathrm{E}(\mathrm{GPa})$ & $\mathcal{\varepsilon}_{\mathrm{b}}(\%)$ \\
\hline AW & 282 & 430 & 201 & 31 \\
PWHT & 282 & 410 & 201 & 34
\end{tabular}




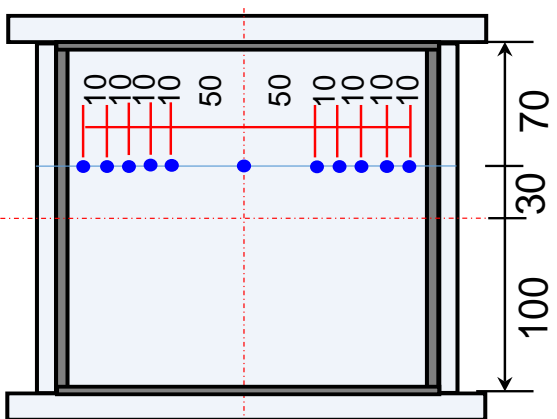

(a)

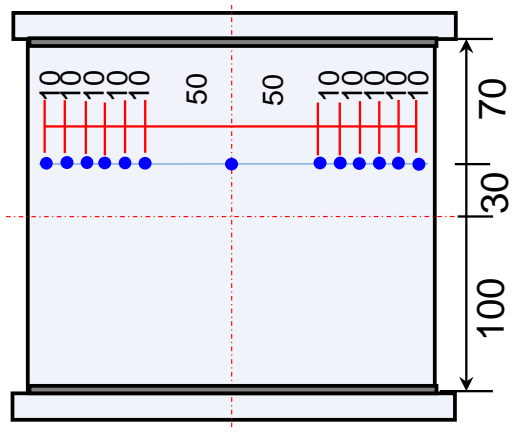

(b)

Figure 8. Positions of XRD measurement. (a) Panel A \& C; (b) Panel B \& D.

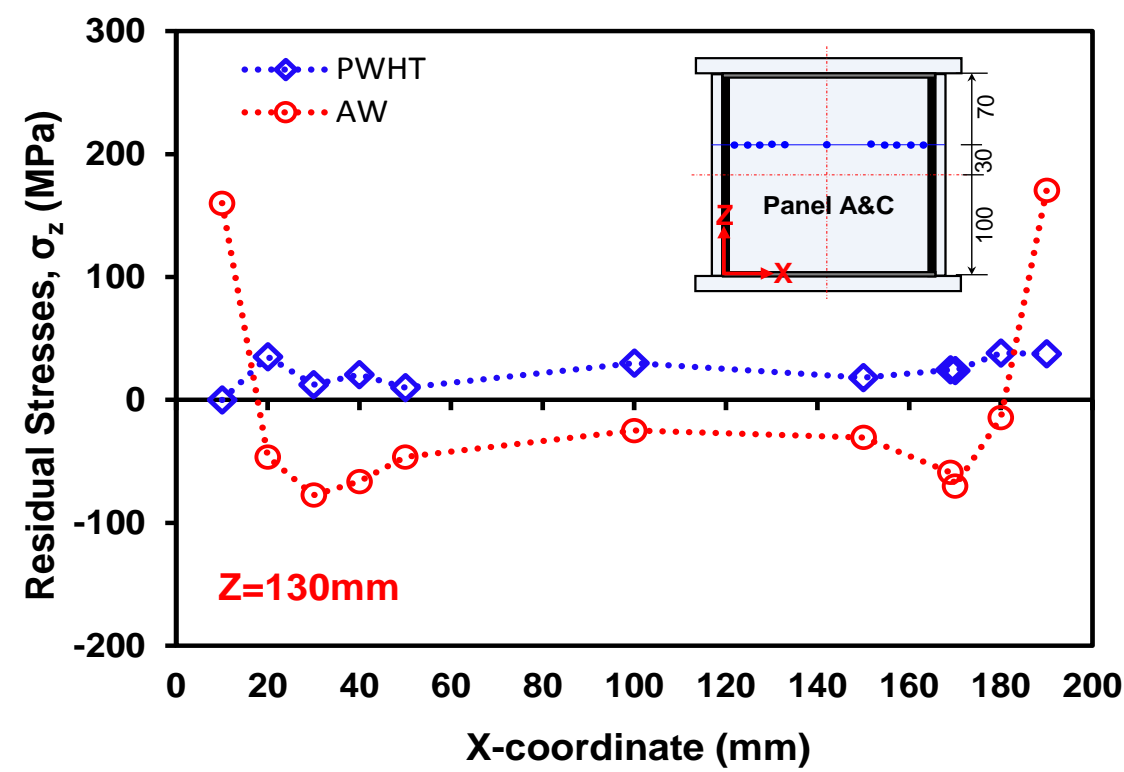

(a)

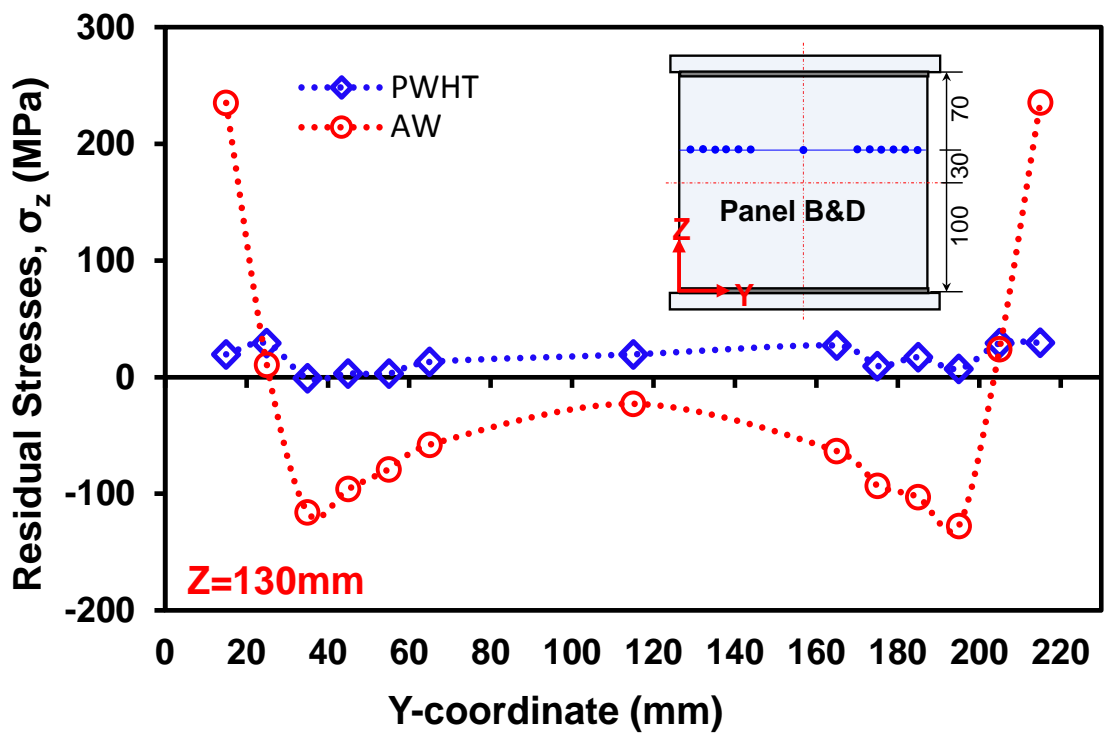

(b)

Figure 9. Longitudinal residual stresses. (a) At panel A \& C; (b) At panel B \& D. 


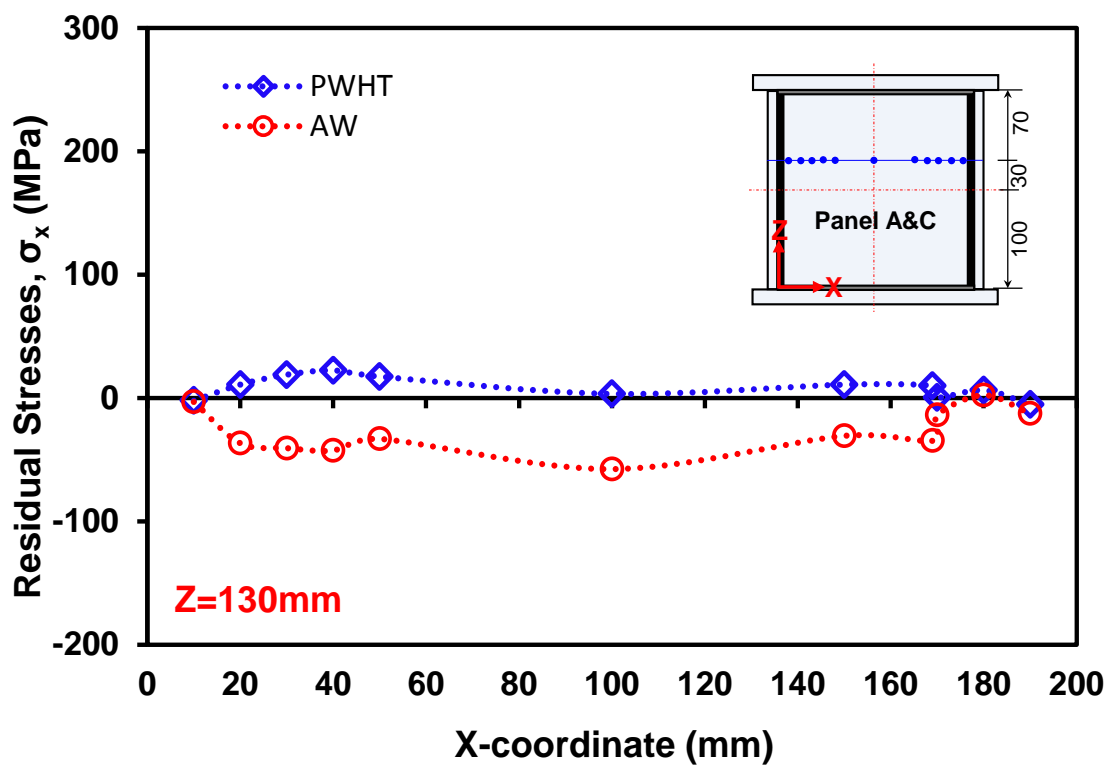

(a)

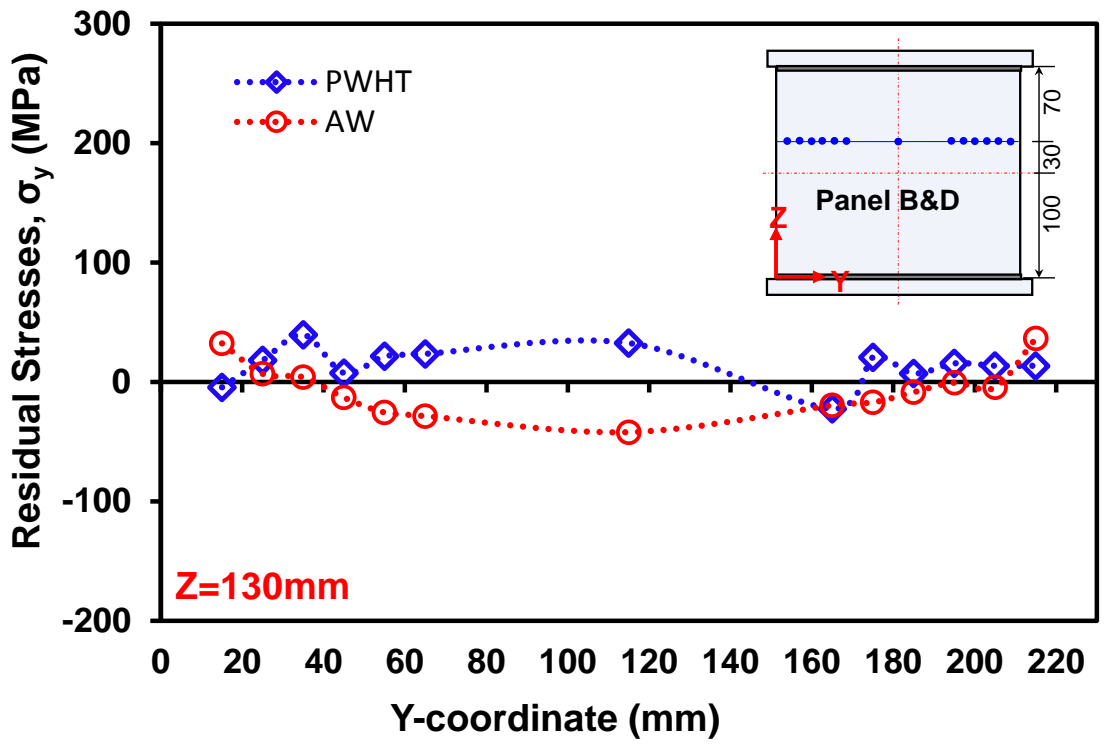

(b)

Figure 10. Transverse residual stresses. (a) At panel A \& C; (b) At panel B \& D.

stress was observed about $77 \mathrm{MPa}$ in panel A \& C and $127 \mathrm{MPa}$ for panel B \& D in the longitudinal direction. However, the PWHT columns reduced the longitudinal residual stresses to $76 \%$ in compression and $90 \%$ in tension of the AW columns. In the case of the transverse direction, the tensile and compressive residual stresses were significantly lower than those from the longitudinal residual stresses since their values were $36 \mathrm{MPa}$ in tension and $42 \mathrm{MPa}$ in compression. It might be due to the fact that heat input was transferred along the arc torch travelling direction. It can be concluded that the PWHT specimens could reduce remarkably both tensile and compressive residual stresses in the longitudinal as well as the transverse directions. 


\section{Monotonic Static Compressive Loading Test}

\subsection{Critical Load Calculation}

Before conducting a monotonic static compressive loading test, slenderness parameter of steel panels was calculated first by using Equation (1) from [24], subsequently Equation (2) was applied to predict the critical load of specimens.

$$
\lambda_{c}=\frac{b}{t} \sqrt{\frac{\sigma_{y}(12)\left(1-v^{2}\right)}{\pi^{2} E k}}
$$

Here,

$\lambda_{c}=$ the slenderness parameter of steel panel

$b=$ the width of steel panel $(\mathrm{mm})$

$t=$ the thickness of steel panel (mm)

$\sigma_{y}=$ the yield stress of steel panel $(\mathrm{MPa})$

$v=$ the Poisson's ratio $(0.3)$

$E=$ the modulus of elasticity $(\mathrm{MPa})$

$k=$ the buckling coefficient (4.0 for simply supported panel)

The slenderness parameter of the selected section was about 0.871 , which means the proposed section would buckle after yielding. Hence, the critical load can be calculated by Equation (2) and eventually the critical load was set as 1092 $\mathrm{kN}$.

$$
P_{c}=\sigma_{y} * A
$$

Here,

$P_{c}=$ the critical load of the specimen $(\mathrm{kN})$

$A=$ the cross-sectional area of the specimen $\left(\mathrm{mm}^{2}\right)$

After computing the critical load, preparation for the monotonic static compressive loading test was carried out as shown in Figure 11. The vertical displacement transducers were placed at the two corners to measure the axial shortening while the lateral displacement transducers were installed at the center of each panel. After preparation of the experimental test setup, the monotonic static compressive load was subjected to the specimens with the capacity of $2000 \mathrm{kN}$

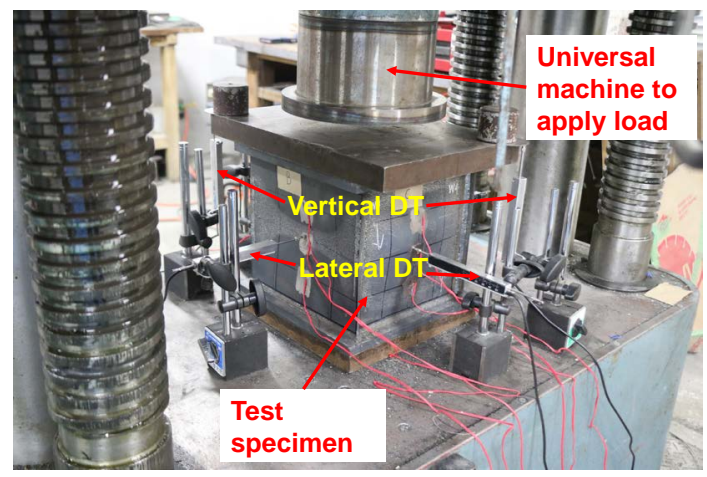

(a)

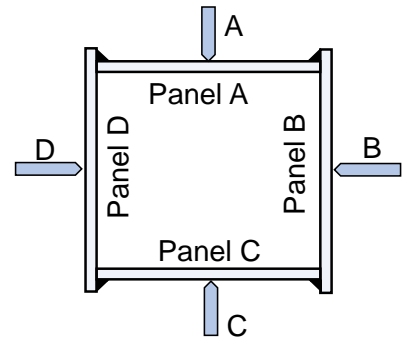

(b)

Figure 11. Experimental test setup. (a) Monotonic static compressive loading test; (b) Lateral displacement transducer position. 
universal machine in order to examine the performance of the specimens with and without PWHT.

\subsection{Axial Load and Shortening}

The compressive behavior of the specimens with and without PWHT was evaluated by means of the load-carrying capacity with respect to the axial shortening and lateral displacement. Summary of the ultimate load of the AW and PWHT specimens are presented in Table 5. The PWHT specimens could achieve closely with the predicted critical load (1092 kN).

Figure 12 represents the axial load versus axial shortening curves. With increasing the applied load, the axial shortening was increased linearly until buckling occurred. An abrupt decrease in load was found in the PWHT specimens after the peak load whereas the AW specimens experienced a gradual decrease in the load until the failure occurred. It was also observed that the PWHT specimens increased slightly their stiffness compared to the AW specimens since the out-of-plane deformations of the PWHT specimens due to the welding process were lower than those of the AW specimens.

It was obvious that the ultimate strength of the PWHT specimens were significantly higher than that of the AW specimens and much more closed to the predicted critical load. The ultimate strength for the PWHT specimens ranged from $952 \mathrm{kN}$ to $1052 \mathrm{kN}$ while the $\mathrm{AW}$ specimens achieved about from $772 \mathrm{kN}$ to 790 $\mathrm{kN}$. Thus, it was clearly revealed that the PWHT specimens could increase the ultimate strength about $32 \%$ compared with the AW specimens. The reason might be that PWHT with the sheet-type ceramic heater released not only the tensile residual stresses but also the compressive residual stresses due to welding of the specimen and this phenomenon tended to delay the yielding of the specimen under compressive load.

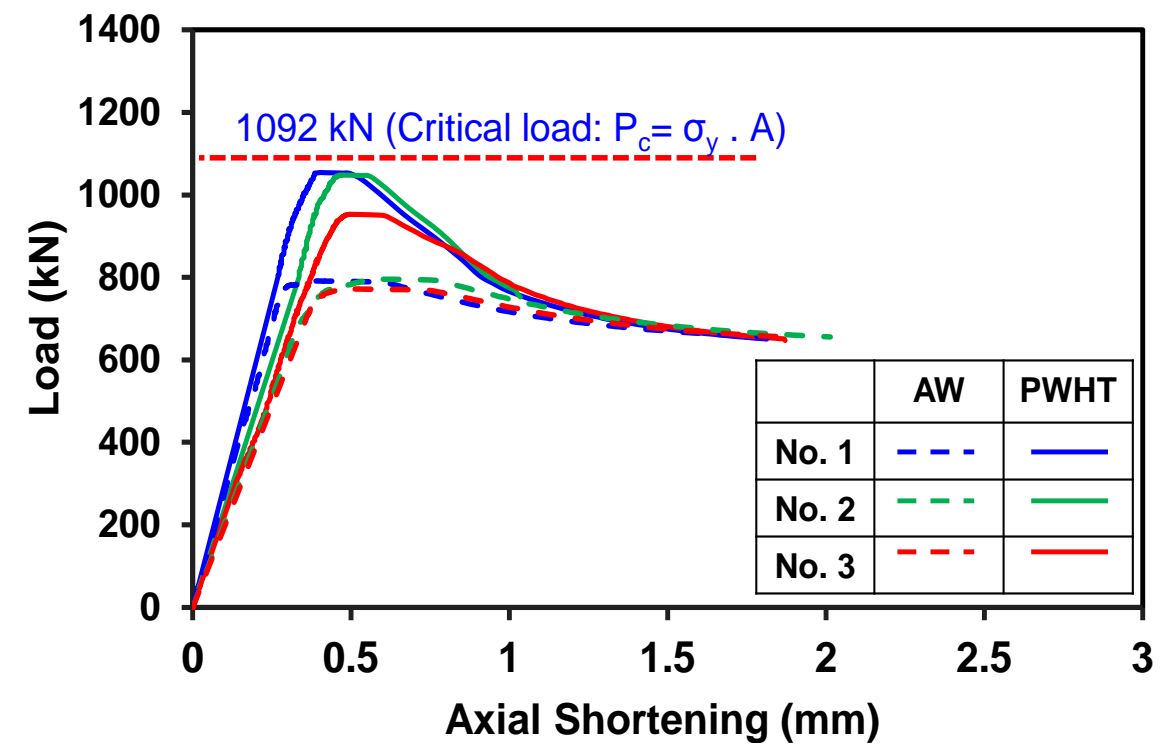

Figure 12. Axial load-shortening curve. 
Table 5. Ultimate load capacity of AW and PWHT columns.

\begin{tabular}{ccc}
\hline & \multicolumn{2}{c}{ Ultimate load $(\mathrm{kN})$} \\
\hline Specimen & AW & PWHT \\
\hline No. 1 & 792 & 1054 \\
No. 2 & 795 & 1049 \\
No. 3 & 772 & 953 \\
\hline
\end{tabular}

\subsection{Axial Load and Lateral Displacement}

Lateral displacements under the compressive load were measured at the center point of the specimens with the lateral displacement transducers in order to examine the buckling mode of the specimens. Comparisons of lateral displacements between the AW and PWHT specimens are depicted in Figure 13. From the figure, it can be clearly seen that all AW and PWHT specimens buckled after yielding has occurred. Lateral deformations in both AW and PWHT specimens were almost zero until the applied load of $600 \mathrm{kN}$ for the AW specimens and 800 $\mathrm{kN}$ for the PWHT specimens respectively. However, after peak load, lateral displacements for all AW and PWHT specimens abruptly increased.

The AW and PWHT specimens produced the same direction of buckling mode under the compressive load. However, the AW specimens underwent buckling at the earlier load stage than the PWHT specimens. It might be because the out-of-plane deformation and the residual stresses induced by welding in AW specimens were higher than those in the PWHT specimens. It was observed that the panel $\mathrm{A}$ and $\mathrm{C}$ deformed the outward direction while the panel $\mathrm{B}$ and $\mathrm{D}$ deformed the inward direction as illustrated in Figure 14.

\section{Conclusions}

In this research, a series of fundamental experimental investigation was conducted in order to examine the effect of PWHT by the sheet-type ceramic heater on the residual stresses, deformation and compressive behaviors of the non-stiffened welded box columns. The main findings of this study are summarized as follows:

1) Even though the sheet-type ceramic heaters were applied the outside faces of the specimens, the heaters provided the same temperature to both contact and non-contact faces of the panels. Therefore, it was proved that the sheet-type ceramic heater was able to control the required temperature history for the PWHT with high accuracy.

2) Not only tensile residual stresses but also compressive residual stresses reduced significantly by PWHT with the sheet-type ceramic heater. The tensile and compressive residual stresses of the PWHT specimens were $90 \%$ and $76 \%$ respectively lower than those of the AW specimens.

3) PWHT could reduce the welding-induced deformation, i.e., the out-of-plane deformation after PWHT was reduced about $22 \%$ compared to that before 


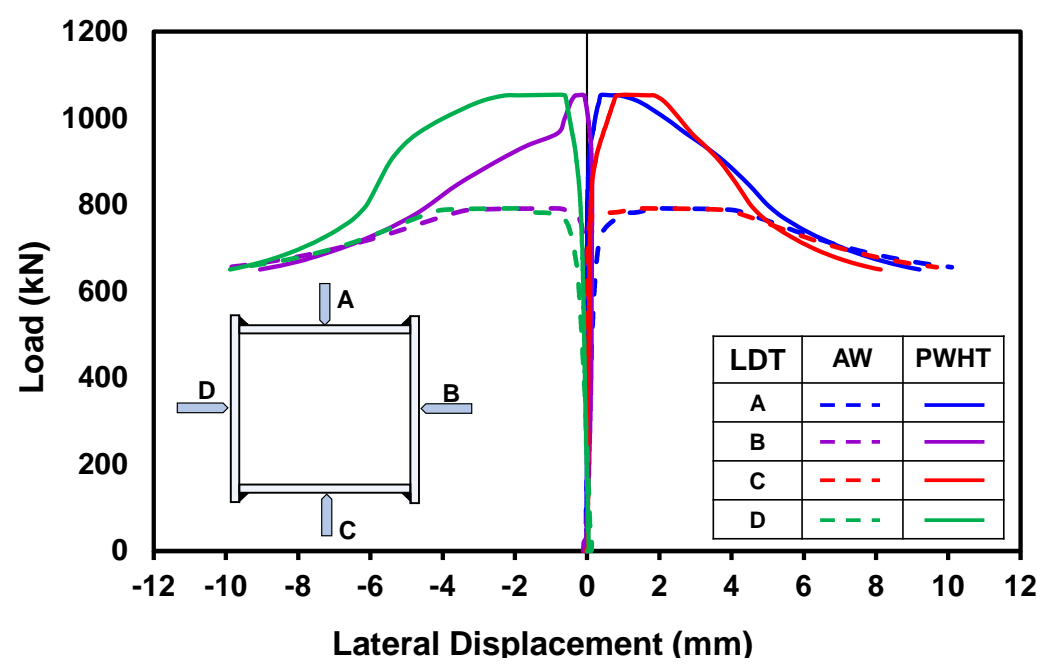

(a)

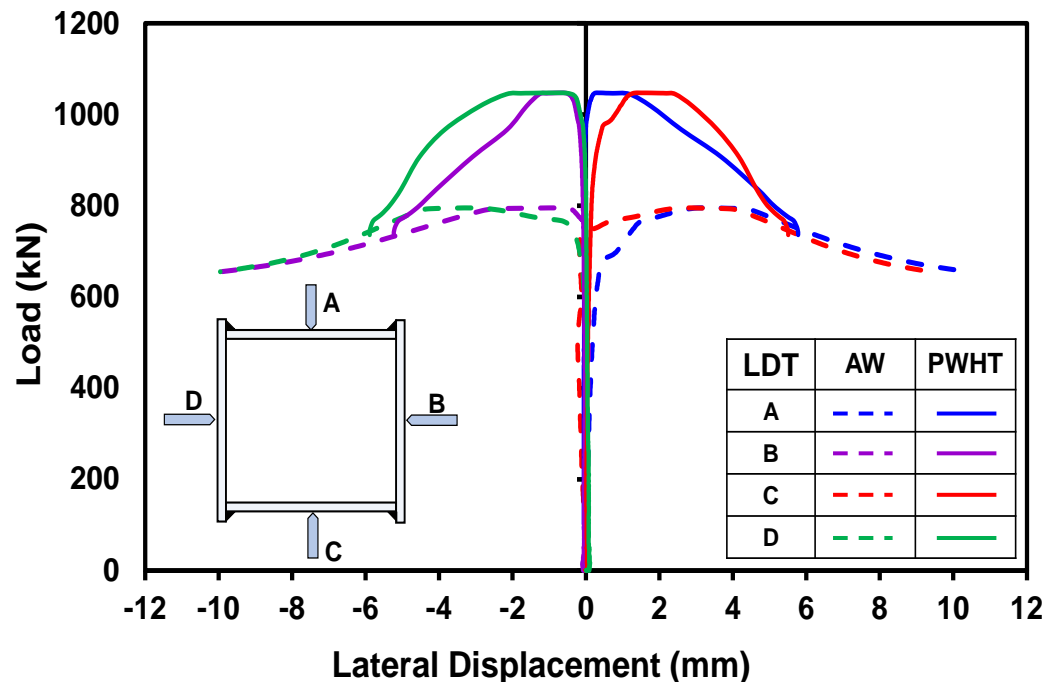

(b)

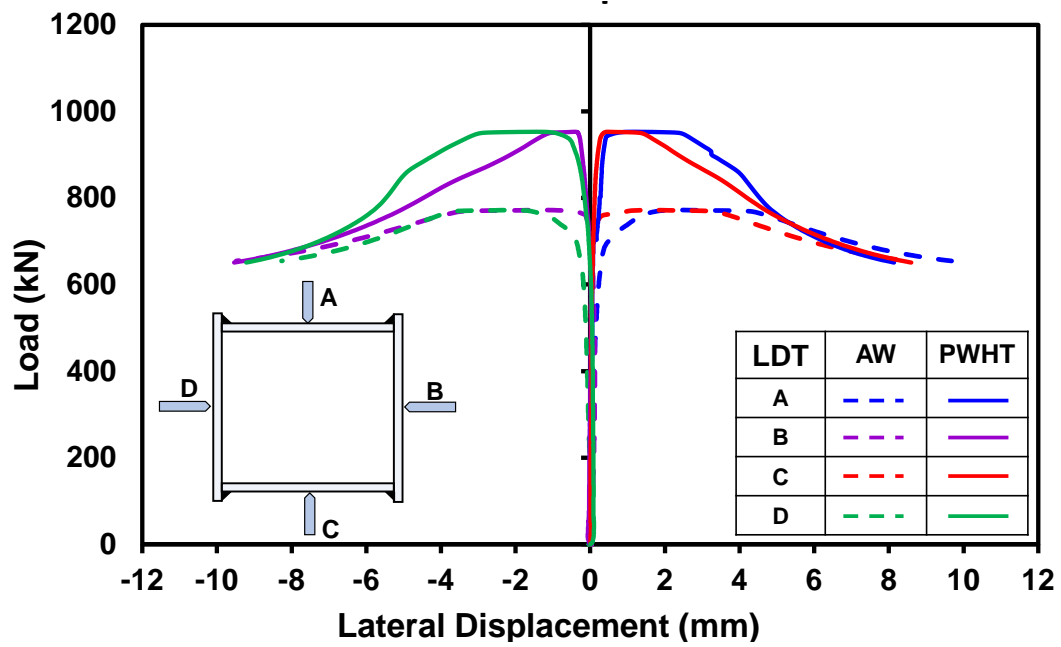

(c)

Figure 13. Axial load-lateral displacement curve. (a) AW1 and PWHT1; (b) AW2 and PWHT2; (c) AW3 and PWHT3. 


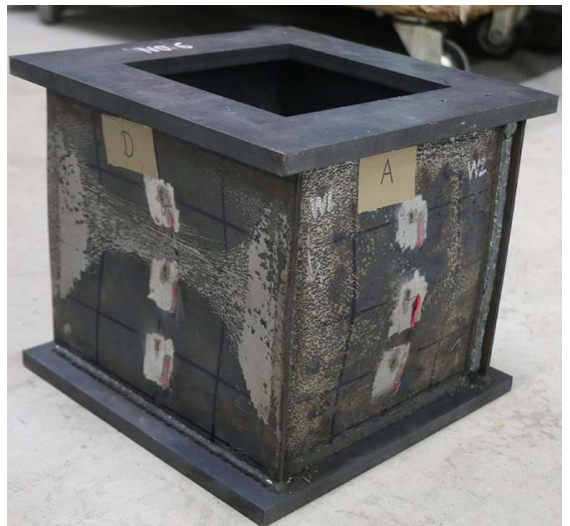

(a)

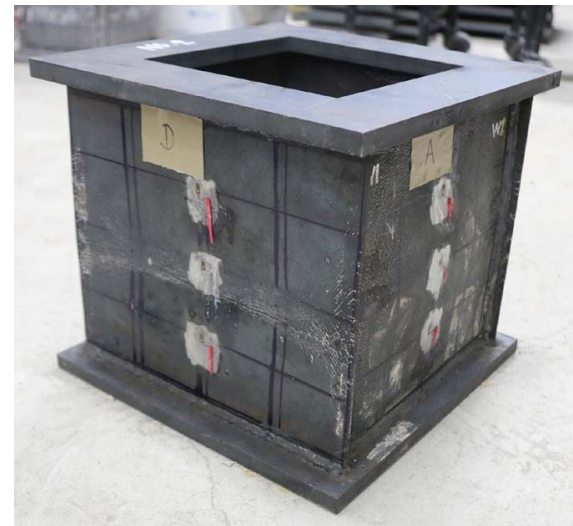

(b)

Figure 14. Final deformed shape after loading. (a) AW; (b) PWHT.

PWHT. Therefore, the PWHT specimens revealed a slight higher stiffness than the AW specimens when applying the monotonic static compressive load on both AW and PWHT specimens. Furthermore, the load level when the lateral deformations of the PWHT specimens increased was much higher than the load level when the AW specimens started to be buckled laterally.

4) The PWHT specimens provided significantly the higher ultimate compressive load capacity compared to the AW specimens and they could achieve closely to the predicted critical load. Moreover, they could enhance the ultimate load capacity about $32 \%$ of the AW specimens.

From this fundamental investigation, it was confirmed that PWHT with sheet-type ceramic heater contributed the substantial improvement to not only the compressive behavior but also the residual stresses and distortion of the welded members. In future, we aim to extend further investigations on the actual larger sizes of the bridge members or more complicated structures.

\section{Acknowledgements}

A part of this research was supported by JSPS KAKENHI Grant Number 16H06098. The PWHT experiment was supported by JEMIX Co. Ltd. and the XRD measurement was supported by Pulstec Industrial Co. Ltd.

\section{References}

[1] Tamakoshi, T., Yokoi, Y. and Ishio, M. (2014) The Feature of Degradation of Steel Highway Bridges Estimated from the Periodic Inspection Data Collected out of Japan. Steel Structure Papers Collection, 21, 99-113. (In Japanese)

[2] Haghani, R., Al-Emrani, M. and Heshmati, M. (2012) Fatigue-Prone Details in Steel Bridges. Buildings, 2, 456-476.

[3] Tanaka, Y. and Murakoshi, J. (2008) Evaluation and Mitigation Methods of Corrosive Environment around Expansion Joints of Highway Bridges. Civil Engineering Journal, 50, 16-19. (In Japanese)

[4] Lee, C.K., Chiew, S.P. and Jiang, J. (2012) Residual Stress Study of Welded High Strength Steel Thin-Walled Plate-to-Plate Joints, Part 1: Experimental Study. 
Thin-Walled Structures, 56, 103-112. https://doi.org/10.1016/j.tws.2012.03.015

[5] Lee, C.K., Chiew, S.P. and Jiang, J. (2012) Residual Stress Study of Welded High Strength Steel Thin-Walled Plate-to-Plate Joints, Part 2: Numerical Modeling. Thin-Walled Structures, 59, 120-131. https://doi.org/10.1016/j.tws.2012.04.001

[6] Jiang, J., Chiew, S.P., Lee, C.K. and Tiong, P.L.Y. (2017) An Experimental Study on Residual Stresses of High Strength Steel Box Columns. Journal of Constructional Steel Research, 130, 12-21. https://doi.org/10.1016/j.jcsr.2016.11.025

[7] Jiang, J., Chiew, S.P., Lee, C.K. and Tiong, P.L.Y. (2017) A Numerical Study on Residual Stress of High Strength Steel Box Column. Journal of Constructional Steel Research, 128, 440-450. https://doi.org/10.1016/j.jcsr.2016.09.015

[8] Wang, Y.B., Li, G.Q. and Chen, S.W. (2012) The Assessment of Residual Stresses in Welded High Strength Steel Box Sections. Journal of Constructional Steel Research, 76, 93-99. https://doi.org/10.1016/j.jcsr.2012.03.025

[9] Ban, H., Shi, G., Shi, Y. and Wang, Y. (2013) Residual Stress of $460 \mathrm{MPa}$ High Strength Steel Welded Box Section: Experimental Investigation and Modeling. Thin-Walled Structures, 64, 73-82. https://doi.org/10.1016/j.tws.2012.12.007

[10] Jiang, J., Lee, C.K. and Chiew, S.P. (2015) Residual Stress and Stress Concentration Effect of High Strength Steel Built-Up Box T-Joints. Journal of Constructional Steel Research, 105, 164-173. https://doi.org/10.1016/j.jcsr.2014.11.008

[11] Dong, P., Hong, J.K. and Bouchard, P.J. (2005) Analysis of Residual Stresses at Weld Repairs. International Journal of Pressure Vessels and Piping, 82, 258-269. https://doi.org/10.1016/j.ijpvp.2004.08.004

[12] Barsan, G.M. and Chiorean, C.G., (1999) Influence of Residual Stress on the Carrying-Capacity of Steel Framed Structures, Numerical Investigation. In: Dubina, D. and Ivany, M., Eds., Stability and Ductility of Steel Structures, Elsevier Science Pub., UK, 317-324. https://doi.org/10.1016/B978-008043016-4/50038-6

[13] Chataigner, S., Dieng, L., Guiot, K. and Grasset, M. (2013) Improving Welded Joint Fatigue Life Using Shot Peening or Grinding, TRB 92nd Annual Meeting, France, Jan 2013, 1-8. https://hal.archives-ouvertes.fr/hal-00851499

[14] Wang, W. and Qin, S. (2016) Experimental Investigation of Residual Stresses in Thin-Walled Welded H-Sections after Fire Exposure. Thin-Walled Structures, 101, 109-119. https://doi.org/10.1016/j.tws.2016.01.005

[15] Zhao, M.S., Chiew, S.P. and Lee, C.K. (2016) Post Weld Heat Treatment for High Strength Steel Welded Connections. Journal of Constructional Steel Research, 122, 167-177. https://doi.org/10.1016/j.jcsr.2016.03.015

[16] Abburi Venkata, A., Kumar, S., Dey, H.C., Smith, D.J., Bouchard, P.J. and Truman, C.E. (2014) Study on the Effect of Post Weld Heat Treatment Parameters on the Relaxation of Welding Residual Stresses in Electron Beam Welded P91 Steel Plates. Procedia Engineering, 86, 223-233. https://doi.org/10.1016/j.proeng.2014.11.032

[17] Dong, P., Song, S. and Zhang, J. (2014) Analysis of Residual Stress Relief Mechanisms in Post-Weld Heat Treatment. International Journal of Pressure Vessels and Piping, 122, 6-14. https://doi.org/10.1016/j.ijpvp.2014.06.002

[18] Qian, Y.W. and Zhao, J.P. (2015) Influence of PWHT on the Residual Stress in Under-Matching Welded Joint. Procedia Engineering, 130, 966-972. https://doi.org/10.1016/j.proeng.2015.12.249

[19] Paradowska, A.M., Price, J.W.H., Kerezsi, B., Dayawansa, P. and Zhao, X.L. (2010) Stress Relieving and Its Effect on Life of Welded Tubular Joints. Engineering Failure Analysis, 17, 320-327. https://doi.org/10.1016/j.engfailanal.2009.06.016 
[20] Mori, H. and Hirohata, M. (2017) Effect of Thermal History by Post-Weld Heat Treatment on Residual Stress Relaxation and Deformation Behavior of Steel Member. Proceedings of 20th Applied Mechanics Symposium, Japan, May 2017, 43-44. (In Japanese)

[21] Hirohata, M. and Itoh, Y. (2015) Residual Stress Relaxation of Box Welded Joints by Portable Heat Source. Journal of Japan Society of Civil Engineers, 71, 208-220. (In Japanese)

[22] Hirohata, M. (2017) Effect of Post Weld Heat Treatment on Steel Plate Deck with Trough Rib by Portable Heat Source. Welding in the World, 61, 1225-1235. https://doi.org/10.1007/s40194-017-0518-x

[23] Japanese Industrial Standard (2009) Method of Post Weld Heat Treatment, JIS Z 3700 .

[24] Salmon, C.G., Johnson, J.E. and Malhas, F.A. (2009) Steel Structures: Design and Behavior. 5th Edition, Pearson Prentice Hall, Upper Saddle River. 